\title{
Producer experience with transitioning to automatic milking: Cow training, challenges, and effect on quality of life
}

\author{
C. Tse, ${ }^{*}$ H. W. Barkema, ${ }^{*}$ T. J. DeVries, $†$ J. Rushen, $\ddagger$ E. Vasseur, $\S$ and E. A. Pajor ${ }^{* 1}$ \\ *Department of Production Animal Health, University of Calgary, Calgary, AB, T2N 4N1, Canada \\ †Department of Animal Biosciences, University of Guelph, Guelph, ON, N1G 2W1, Canada \\ ¥Faculty of Land and Food Systems, University of British Columbia, Vancouver, BC, V6T 1Z4, Canada \\ §Department of Animal Science, McGill University, Ste. Anne de Bellevue, QC, H9X 3V9, Canada
}

\section{ABSTRACT}

Despite the growing popularity of automatic milking systems (AMS), or milking robots, in Canada, little documentation is available on how Canadian dairy producers experience the transition to this milking technology. The objective of this national study was to document the experiences of Canadian dairy producers during the transition to, and use of, AMS. This paper reports on producers' experiences with cow training, challenges during the transition and their solutions, and effect of the AMS on quality of life. The AMS producers $(\mathrm{n}=217)$ were surveyed from 8 Canadian provinces. Overall, producers experienced a positive transition to AMS. Producers perceived that AMS improved profitability, quality of their lives and their cows' lives, and had met expectations, despite experiencing some challenges during transition such as learning to use the technology and data, cow training, demanding first few days, and changing health management. Less than half of the AMS producers (42\%) trained cows or heifers to use the AMS before the first milking with the robot. Producers who implemented training before first milking reported that it took an average of $1 \mathrm{wk}$ to train a cow or heifer to use the AMS. Producers reported it took a median of $30 \mathrm{~d}$ for an entire herd to adapt to the AMS, whether or not cow training took place. On average, $2 \%$ of a herd was culled for not adapting, or not voluntarily milking, when otherwise physically and behaviorally normal. With AMS, producers suggested they gained more time flexibility, found work to be less stressful and physically demanding, found employee management easier, and had improved herd health and management. The vast majority (86\%) of producers would recommend others to transition to AMS.

Received February 27, 2018.

Accepted June 9, 2018.

${ }^{1}$ Corresponding author: eapajor@ucalgary.ca
Key words: robotic milking, adoption, precision dairying

\section{INTRODUCTION}

In Europe, the United States, Australia, and New Zealand, automatic milking systems (AMS), or milking robots, have had a positive effect on the quality of producers' lives (Reinemann and Smith, 2000; Bergman and Rabinowicz, 2013; Molfino et al., 2014; Woodford et al., 2015). When operating optimally, AMS have many benefits: improved cow health, easier health detection (Tse et al., 2017), increased milk production (Tse et al., 2018), more interesting/less routine activities (Woodford et al., 2015), needing less labor (Hansen, 2015), and a more flexible lifestyle (de Koning, 2010). Many of these benefits may only become apparent after a transitional period. This transitional period has yet to be documented in detail for Canadian AMS herds.

Training is an important aspect of transitioning to AMS and involves exposing the animal to the sounds and mechanical movements of the AMS before first milking (Jago and Kerrisk, 2011). Introducing heifers to the AMS before calving has been shown to have a positive effect on milking intervals, frequency of feeding, and milk production after calving (Widegren, 2014). The AMS companies recommend following a cow-training program to help with the transition to and use of AMS. However, the programs are not standardized, often differing in method, duration, and specificity, and little is known about whether or not producers invest time in cow training or what methods they use.

During the transition to AMS, producers experience many changes (e.g., building modifications and cow health management; Tse et al., 2017), some of which are more challenging than others. This technology is growing in popularity in Canada: the proportion of Canadian dairy farms that use AMS grew from 5.6\% (493 farms) in 2014 to $6.8 \%$ (574 farms) in 2015 (Canadian Dairy Information Centre, 2016). Still, limited documentation is available on how producers experience the 
transition and how AMS has affected the quality of Canadian dairy producers' lives. The objective of this study was, therefore, to determine how Canadian dairy producers experienced the transition to, and use of, AMS, focusing on experiences with cow training, challenges during the transition, and effect on quality of life.

\section{MATERIALS AND METHODS}

This research was part of a larger study aimed at determining the effect of transitioning to AMS on producers' perceptions of change in farm management and cow health in the Canadian dairy industry (Tse et al., 2017), as well as economic profitability (Ferland et al., 2016). Methodology of the study is presented in detail in Tse et al. (2017, 2018). Institutional human ethics certification was received before contacting participants (University of Calgary, certification no. REB14-0149_ MOD1). Consent was received before each survey. Surveys that were terminated before completion, as well as farms that reverted back to conventional milking systems $(\mathrm{n}=3)$, were excluded from the study.

\section{Farm Selection and Data Collection}

In short, provincial milk boards (Alberta Milk, Edmonton, AB, Canada, and Dairy Farmers of Manitoba, Winnipeg, MB, Canada), Lely Canada (Woodstock, ON, Canada), and DeLaval Canada (Peterborough, ON, Canada) provided access to Canadian producers who were using AMS. Producers' contact information was compiled to make our sampling frame. All 530 AMS producers in our sampling frame were contacted and data were collected on those willing to participate. The response rate was $41 \%$. Surveys were conducted from May 2014 to the end of June 2015. The AMS farms were surveyed in British Columbia $(\mathrm{n}=8)$, Alberta $(\mathrm{n}=43)$, Saskatchewan $(\mathrm{n}=7)$, Manitoba $(\mathrm{n}=12)$, Ontario $(\mathrm{n}=73)$, Quebec $(\mathrm{n}=66)$, New Brunswick, and Nova Scotia by telephone, email, and in person. New Brunswick and Nova Scotia were referred to collectively as the Maritimes $(\mathrm{n}=7)$. One respondent chose not to specify their province of residence. Producers were initially contacted by phone with the General Survey and those who were interested were emailed a link with follow-up questions. Producers who could not be reached by phone were emailed a link to the Combined Survey, which contained the General Survey and follow-up questions. Most respondents completed the survey over the phone $(\mathrm{n}=149)$, whereas 15 respondents completed the survey exclusively online and 5 respondents completed it exclusively in person. A total of 37 respondents completed the survey over the phone and the follow-up questions online, and 11 respondents completed the survey over the phone and the follow-up questions in person.

Interviewers were trained to explain at the beginning of each phone or in-person survey that the study was being conducted through the University of Calgary (independent of AMS companies), allowing them no risk or benefit by giving an honest account of the transition. This would have helped to minimize social desirability bias, which is the tendency to respond differently in the presence of an interviewer so one appears in a favorable light (Green and Thorogood, 2013), as well as reduce postproduct rationalization, which is a bias that causes a purchaser of an expensive product to ignore product faults as a way to justify their purchase (Cohen and Goldberg, 1970). However, only having access to farms that successfully transitioned (or were still transitioning at the time) meant collecting data that were likely partial to positive outcomes. Interviewers were also trained to ask questions exactly as scripted in the final version of the survey and to provide standardized prompts and clarifications only when necessary, to limit the effects of interviewer bias.

\section{Surveys}

The mixed-methods surveys are available online with Tse et al. (2017; "General Survey," Supplemental File Appendix I, https://doi.org/10.3168/jds.2016-11521, and "Combined Survey," Supplemental File Appendix II, https://doi.org/10.3168/jds.2016-11521). To reduce the chances of respondents misinterpreting questions, a pilot study was conducted and questions that caused confusion were modified.

The General Survey covered the following topics that were addressed in this manuscript: experience with cow training, challenges and solutions experienced during the transition, changes in quality of life, and overall level of satisfaction with AMS. The Combined Survey contained the same questions from the General Survey, as well as more in-depth questions related to the topics covered in the General Survey. The follow-up to the General Survey consisted of questions exclusive to the Combined Survey. Sample size varied per question, as respondents had the option to skip questions. Giving respondents the option to skip questions helped to minimize recall bias. The General Survey questions had 217 respondents, and the follow-up questions, which were specific to the Combined Survey, had 69 respondents.

\section{Statistical Analyses}

Statistical analyses were performed with $\mathrm{R}$ version 3.2.2 (The $\mathrm{R}$ Foundation for Statistical Computing 
Platform, 2015, Vienna, Austria). A $P$-value $<0.05$ was considered statistically significant. Data analysis primarily included descriptive statistics (means, SE, medians, 1st-3rd quartiles, and percentages). Results with normal distribution are presented as means \pm standard error, and results with nonnormal distribution are presented as medians with 1st-3rd quartiles (IQR). Because producers were given the option to skip questions without providing an answer, sample sizes were calcuated as the number of respondents per question.

Brand comparisons were only made between Lely ( $\mathrm{n}$ $=165)$ and DeLaval $(\mathrm{n}=45)$ due to the small sample sizes of Insentec $(\mathrm{n}=2)$ and BouMatic $(\mathrm{n}=2)$ users. Three respondents chose not to indicate which brand AMS they were operating at the time. Chi-squared test, or Fisher's exact test for cases that involved frequency counts $<5$, was used to compare categorical, frequency data (e.g., when comparing by brand the proportions of respondents who train cows, heifers, or both, to use AMS). Wilcoxon rank sum and signed rank test was used to compare 2 medians of variables that were not normally distributed (e.g., comparing by brand the number of days to train cows, the number of days to train heifers, and the proportion of herd culled for not adapting).

Producers were asked to score 4 statements ("AMS has improved profitability," "AMS has improved quality of my life," "AMS has improved quality of my cows' lives," and "AMS has met expectations") on a scale from 1 (strongly disagree) to 5 (strongly agree). Kendall's tau was used to measure the strength of associations between the scores of each statement. Spearman's correlation coefficient was used to measure the strength of associations between scores and time since transition to AMS (inclusive of all respondents), herd size, and producer age group $(<35,35-45,46-56,>56 \mathrm{yr})$.

Open-ended questions were analyzed with inductive, thematic analysis (Green and Thorogood, 2013). Responses for open-ended questions were coded for re-occurring themes or patterns, which were then quantified for the purpose of describing how common those themes were among our respondents (Green and Thorogood, 2013).

\section{RESULTS}

\section{Information Sources}

In total, 217 producers were surveyed in 8 provinces across Canada. Complete demographic description of respondents can be found in Tse et al. (2017). The most commonly used sources of information that producers consulted before adopting AMS were as follows: supplier
Table 1. Sources of information Canadian dairy producers consulted before adopting automatic milking system (AMS; respondents chose $\geq 1$ preferred information source; $\mathrm{n}=78$ respondents)

\begin{tabular}{lcc}
\hline & \multicolumn{2}{c}{ Respondents } \\
\cline { 2 - 3 } Information source & No. & $\%$ \\
\hline Supplier of AMS ("dealer") & 58 & 74 \\
Other farmers & 57 & 73 \\
Individual farm visits (veterinarians, consultants) & 21 & 27 \\
Technical farm magazines and newspapers & 21 & 27 \\
On-farm demonstrations/workshops & 16 & 21 \\
Local/regional meetings (educational or industrial) & 11 & 14 \\
Other & 8 & 10 \\
Instructional videos and DVDs & 5 & 6 \\
Research papers or university extension fact sheets & 3 & 4 \\
Newsletters & 2 & 3 \\
Webinars & 2 & 3 \\
TV or radio programs & 1 & 1 \\
Blogs & 1 & 1 \\
Podcasts & 0 & 0 \\
None of the above & 0 & 0 \\
\hline
\end{tabular}

of AMS, other farmers, individual farm visits (veterinarians or consultants), and technical farm magazines and newspapers (Table 1). Sources that producers reported as "other" in Table 1 included traveling to Europe to visit AMS farms and searches on the Internet. The least consulted information sources were TV or radio programs, blogs, and podcasts. Overall, $93 \%$ of producers were satisfied with the level of support received from their preferred sources of information. Median level of satisfaction with the support provided by the professional advisors such as veterinarians, consultants, and specialists (56 respondents) was 4 (IQR: $3-4)$ on a scale of 1 (very dissatisfied) to 5 (very satisfied).

\section{Cow Training}

Overall, $42 \%$ of producers trained heifers, cows, or both, before first milking with the robot (Table 2). The remaining $58 \%$ of producers fetched cows to bring them to the robot and allowed milking to occur during the cows' first experience with the robot. Eighteen percent of AMS farms trained cows before calving, with no differences by brand $(P=0.35)$. Producers often provided feed in the AMS during training of cows and heifers, but were less likely to have the robot arm spray teats with disinfectant (to create awareness of the arm) as part of cow and heifer training (Table 2). Almost all producers $(99 \%)$ supervised a cow's first milking with AMS. Small training groups of $<20$ cows were more common ( $63 \%$ of respondents) than group sizes of $\geq 20$ (37\%). Farms that trained mature cows to use AMS ( $\mathrm{n}=42$ respondents) required cows to visit the AMS a median of 2 times/d (IQR: 2-3 times/d) during the first and second week of training, with no differences by 
brand of $\operatorname{AMS}(P \geq 0.10)$. The majority of producers $(60 \%)$ allowed cows to be more than $6 \mathrm{~h}$ late before fetching them during the first 2 wk of training.

For producers who used a training program, it took a median of $7 \mathrm{~d}$ to train a cow or heifer (Table 2). Comparatively, producers who did not train cows or heifers before first milking with the AMS believed that it would take $7 \mathrm{~d}$ (IQR: $3-10 \mathrm{~d}$ ) to train cows and $7 \mathrm{~d}$ (IQR: $5-10 \mathrm{~d}$ ) to train heifers. It was estimated for an entire lactating herd a median of $30 \mathrm{~d}$ (IQR: 14-76 d) was needed to adapt to and use the AMS during the transition. The number of days it took for an entire herd to adapt to the AMS did not differ if training of cows, heifers, or both, had or had not occurred $(P \geq$ $0.30)$. No brand differences were detected in the number of days for a herd to adapt $(P=0.61)$. The median proportion of a herd culled for not adapting (i.e., for not voluntarily milking while otherwise normal in appearance and behavior) was $2 \%$, with a range of 0 to $40 \%$. No brand differences were detected in proportion of a herd culled for not adapting (Table 2).

\section{Challenges and Their Solutions During Transition}

The AMS producers encountered a wide variety of challenges when transitioning to and using AMS (Table 3 ). Some of the main challenges producers experienced during transition included: learning to use the AMS (some found the technology complicated and felt overwhelmed with the amount of data it produced); cow training (breaking the cows' routine and difficulty training heifers and old cows); issues with nutrition (balancing feed and the cost of feed); trusting the AMS and changing mindset (accepting that the farm requires a different style of management and is now more computer-reliant, and having to change their own routines); having an extremely demanding first few days/weeks at start-up (needing to recruit extra help or not having enough help, requiring an intense amount of physical labor to push cows through the AMS, and trying to keep employees motivated); and having to change health management (to deal with feet/leg, heat detection, reproduction and mastitis issues, and

Table 2. Training practices used by automatic milking system (AMS) producers

\begin{tabular}{|c|c|c|c|}
\hline \multirow[b]{2}{*}{ Item } & \multicolumn{2}{|c|}{ Brand $^{1}$} & \multirow[b]{2}{*}{ Overall $^{2}$} \\
\hline & Lely & DeLaval & \\
\hline \multicolumn{4}{|l|}{ Respondents who... ${ }^{3}(\%)$} \\
\hline Train cows only & 6 & 4 & 6 \\
\hline Train (lactating) heifers only & 21 & 29 & 22 \\
\hline Train both cows and (lactating) heifers & 13 & 16 & 14 \\
\hline Do not train at all & 59 & 51 & 58 \\
\hline Respondents (no.) & 165 & 45 & 214 \\
\hline \multicolumn{4}{|l|}{ Provide feed during training (\%) } \\
\hline $\begin{array}{l}\text { Cows } \\
\text { (respondents, no.) }\end{array}$ & $\begin{array}{c}92 \\
(25)\end{array}$ & $\begin{array}{l}86 \\
(14)\end{array}$ & $\begin{array}{l}88 \\
(42)\end{array}$ \\
\hline $\begin{array}{l}\text { Heifers } \\
\text { (respondents, no.) }\end{array}$ & $\begin{array}{c}92 \\
(25)\end{array}$ & $\begin{array}{l}85 \\
(13)\end{array}$ & $\begin{array}{c}90 \\
(40)\end{array}$ \\
\hline \multicolumn{4}{|l|}{ Spray teats during training (\%) } \\
\hline $\begin{array}{l}\text { Cows } \\
\text { (respondents, no.) }\end{array}$ & $\begin{array}{l}55 \\
(22)\end{array}$ & $\begin{array}{c}31 \\
(13)\end{array}$ & $\begin{array}{c}47 \\
(38)\end{array}$ \\
\hline $\begin{array}{l}\text { Heifers } \\
\text { (respondents, no.) }\end{array}$ & $\begin{array}{l}45 \\
(25)\end{array}$ & $\begin{array}{l}38 \\
(13)\end{array}$ & $\begin{array}{c}45 \\
(38)\end{array}$ \\
\hline \multicolumn{4}{|l|}{ Median $\left[\mathrm{IQR},{ }^{4}\right.$ respondents (no.)] days to train } \\
\hline Cows $^{5}$ & $\begin{array}{l}7 \\
(3-10,30)\end{array}$ & $\begin{array}{l}5 \\
(3-11,7)\end{array}$ & $\begin{array}{l}7 \\
(3-10,38)\end{array}$ \\
\hline Heifers & $\begin{array}{l}6 \\
(3-9,55)\end{array}$ & $\begin{array}{l}7 \\
(4-7,17)\end{array}$ & $\begin{array}{l}7 \\
(3-9,73)\end{array}$ \\
\hline Median proportion of herd culled, \% [IQR, respondents (no.)] & $\begin{array}{l}1 \\
(0-3,97)\end{array}$ & $\begin{array}{l}3 \\
(2-5,31)\end{array}$ & $\begin{array}{l}2 \\
(1-3,130)\end{array}$ \\
\hline
\end{tabular}

${ }^{1}$ Only Lely (Woodstock, ON, Canada) and DeLaval (Peterborough, ON, Canada) were tested for differences (where sample sizes were $>10$ ) due to small sample sizes of other brands. Medians and proportions within a row are not significantly different $(P<0.05)$.

${ }^{2}$ Overall values include other brands (Insentec, Marknesse, the Netherlands, and BouMatic, London, ON, Canada) and anonymous respondents.

${ }^{3}$ There were no differences in distribution of respondents by brand.

${ }^{4} \mathrm{IQR}=1$ st-3rd quartiles.

${ }^{5}$ Item was not tested for brand differences due to small sample sizes. 
Table 3. Challenges experienced by producers $(\mathrm{n}=201)$ during the transition to and use of automatic milking systems $($ AMS $)$ and respective solutions

\begin{tabular}{|c|c|}
\hline Challenge (no. of respondents with that challenge) ${ }^{1}$ & Solutions (no. of respondents with those solutions) \\
\hline Feed balance and nutrition $(\mathrm{n}=31)$ & $\begin{array}{l}\text { Working with a nutritionist or feed consultant (18), trial and error (6), switching feed } \\
\text { companies (4), being a better observer (3), talking to other AMS farmers (in Canada } \\
\text { and abroad; } 2 \text { ) }\end{array}$ \\
\hline Demanding first few days/weeks $(\mathrm{n}=30)$ & $\begin{array}{l}\text { Time, patience, and effort (15), recruiting extra help (10), focusing on working } \\
\text { efficiently (1), educating and encouraging employees (1), suggests transitioning in } \\
\text { March versus May in order for the transition to be done before field work season }(1)^{2}\end{array}$ \\
\hline Changing health management $(\mathrm{n}=21)$ & $\begin{array}{l}\text { Feet and leg: trim and check hooves often (be proactive; } 7 \text { ), implement use of } \\
\text { footbath ( } 3 \text { ) } \\
\text { Heat detection: be a better observer }(2) \text {, use activity monitor }(2) \\
\text { Reproduction: implement new observation system }(2) \text {, learn to plan ahead (1) } \\
\text { Mastitis: be more vigilant and proactive }(2)\end{array}$ \\
\hline Building modifications $(\mathrm{n}=17)$ & $\begin{array}{l}\text { Time to plan it out well (8), effort to "just do it" (4), talking to other AMS farmers } \\
(2) \text {, help from dealer }(1)^{2}\end{array}$ \\
\hline Technical issues $(\mathrm{n}=17)$ & $\begin{array}{l}\text { Technical issue-specific solution }(3) \text {, self-taught to fix issues }(2) \text {, help from dealer }(2) \text {, } \\
\text { talking to other AMS farmers }(1) \text {, replacing the robot }(1) \text {, preventative maintenance } \\
(1) \text {, trying not to get frustrated }(1)^{2}\end{array}$ \\
\hline Feet and leg issues $(\mathrm{n}=16)$ & $\begin{array}{l}\text { Implement more frequent trimming and use of footbath (preventative maintenance; } \\
10 \text { ), install nonslip mats }(1) \text {, build pack pen for lame cows }(1) \text {, changed diet }(1)^{2}\end{array}$ \\
\hline Being on call $(\mathrm{n}=15)$ & $\begin{array}{l}\text { Time to adjust and accept it ( } 5) \text {, hire help }(2) \text {, stay on top of maintenance }(2) \text {, do } \\
\text { better at checking and cleaning the AMS unit before bed }(1)^{2}\end{array}$ \\
\hline $\begin{array}{l}\text { Poor service from dealer and lack of support from } \\
\text { others }(\mathrm{n}=14)\end{array}$ & $\begin{array}{l}\text { Learning to solve problems by oneself (4), talked to other farmers }(2) \text {, switching } \\
\text { dealers (1), making complaints noticed by dealer }(1)^{2}\end{array}$ \\
\hline Decreased milk quality $(\mathrm{n}=9)$ & $\begin{array}{l}\text { Changing management (e.g., routing cows differently within the barn so they can be } \\
\text { examined easier and more frequently) (2), culling high SCC cows }(1) \text {, giving it time } \\
\text { as SCC returned to normal on its own (1), dealer fixed spray apparatus }(1)^{2}\end{array}$ \\
\hline
\end{tabular}

${ }^{1}$ Respondents were allowed to list more than one challenge (i.e., number of respondents for each challenge are not necessarily independent of one another).

${ }^{2}$ Some producers did not have a solution to this challenge.

to manage cow health more on an individual animal basis). Other challenges that were experienced by a very small number of producers (1 to 2 respondents/ challenge) included general maintenance for the AMS, having little knowledge about cows as a first-time dairy owner, managing cow traffic to the AMS, making too much milk, needing more robots at start-up, and simply not enjoying the technology. Common solutions to most of the listed challenges in Table 3 were time and patience, being proactive, and being willing to ask for help from others (e.g., equipment dealer, other AMS farmers, nutritionists, and so on).

\section{Quality of Life}

Overall, producers scored all improvement and expectation statements positively (median scores of 4 or
5 on the scale of 1 to 5 ), indicating a high level of satisfaction (Table 4). Lely users more strongly agreed that their AMS had improved their quality of life, and more strongly agreed that their AMS had met expectations, when compared with DeLaval users (Table 4).

A weak but significant, negative correlation was present between scores given to "AMS has met expectations" and time since transition $\left(\mathrm{r}_{\mathrm{s}}=-0.16, P=\right.$ 0.02). A weak, negative correlation was also present between herd size and scores given to "AMS has improved quality of my life" $\left(\mathrm{r}_{\mathrm{s}}=-0.17, P=0.01\right)$ and "AMS has met expectations" $\left(\mathrm{r}_{\mathrm{s}}=-0.15, P=0.03\right)$. No differences were observed between improvement and expectation scores and the producers' age groups $(P \geq$ $0.17)$. A positive correlation was present between every comparison of the 4 improvement and expectation statements (Table 5). 
Table 4. Average and median quality of life statement scores by brand and across all brands

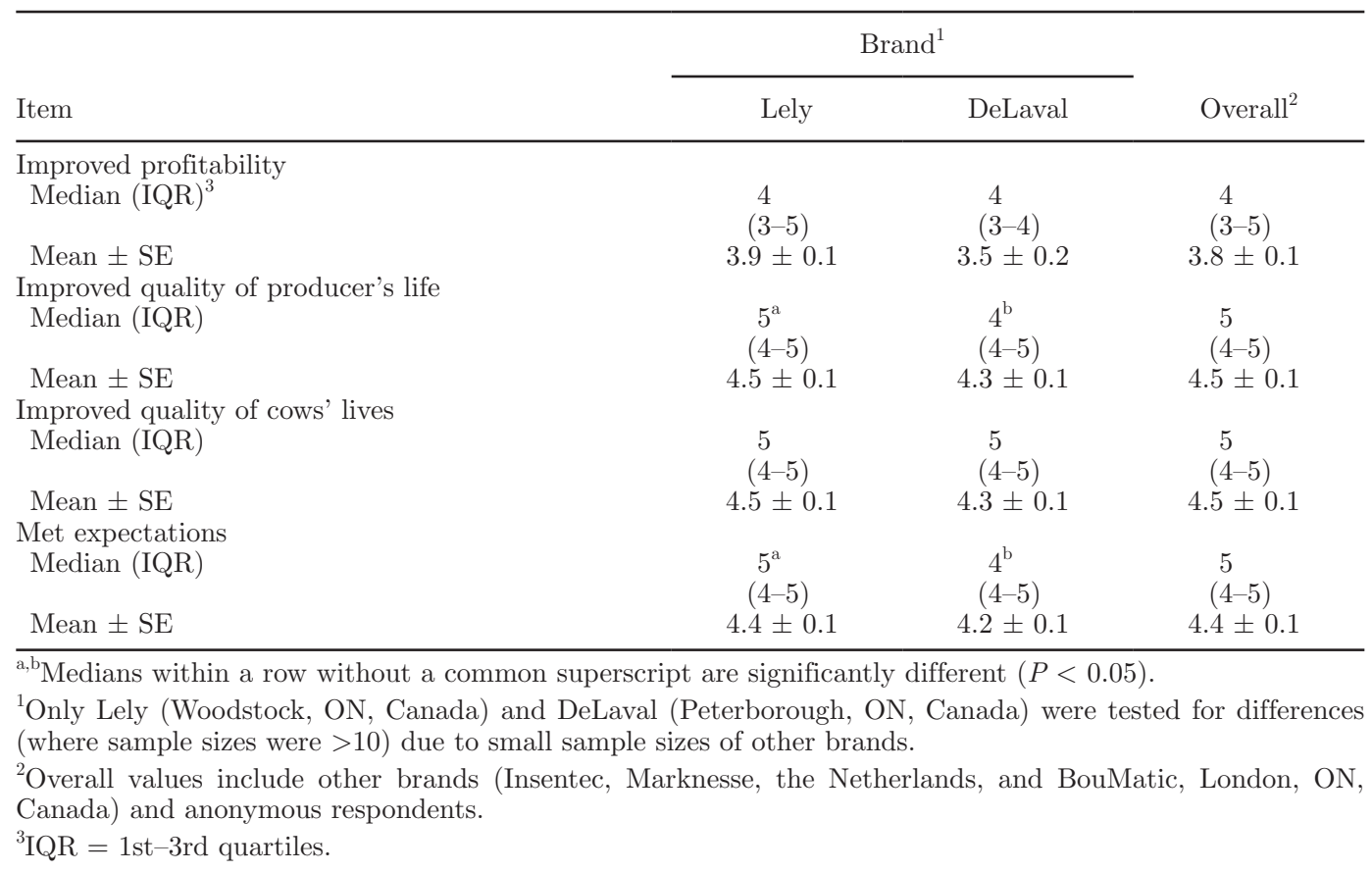

The most commonly reported improvements to quality of life since transitioning to AMS were increased flexibility with time (97\% of producers), work being less stressful and less physically demanding on their body $(37 \%)$, easier employee management $(14 \%)$, and indirectly through improved herd health and better herd management (11\%). Some producers elaborated that they can now spend more time with their families, attend meetings, get more sleep, and have time for other farm chores and crop duties. With less physical work required, a few producers noted an improvement in their health, as they indicated they previously experienced neck and back issues when milking with the parlor. Employee management was described as being easier with AMS for several reasons: some producers no longer have any employees to deal with or have fewer employees; not needing to rely on employees as much with robotic milking; and being able to hire and train employees with limited cattle experience relatively quickly, if the producer would like to or needs to go away for a while. Other improvements to quality of life included greater job satisfaction and better work conditions, increased production, profit, and efficiency, and last, having greater involvement of and interest from the younger generation.

When producers were asked the question "On a scale of 1-5 (1-very small workload, to 5-very heavy workload), how would you characterize your average annual workload after switching to AMS?" the median score provided was 3 (IQR: 2-3). No difference was detected between brands of AMS $(P=0.73)$. Switching to AMS was only part of a farm succession plan or strategy for $46 \%$ of producers, with no differences by brand $(P=$ $0.29)$.

Table 5. Associations between producers' improvement and expectation statement scores (scored on a scale of 1-strongly disagree, to 5-strongly agree) using Kendall's $\tau$

\begin{tabular}{|c|c|c|c|c|}
\hline $\operatorname{AMS}^{1}$ has... & $\begin{array}{l}\text { Improved } \\
\text { profitability }\end{array}$ & $\begin{array}{l}\text { Improved quality } \\
\text { of my life }\end{array}$ & $\begin{array}{l}\text { Improved quality } \\
\text { of my cows' lives }\end{array}$ & $\begin{array}{c}\text { Met } \\
\text { expectations }\end{array}$ \\
\hline Improved profitability & - & $\begin{array}{l}\tau=0.20 \\
P=0.001\end{array}$ & $\begin{array}{l}\tau=0.30 \\
P<0.001\end{array}$ & $\begin{array}{l}\tau=0.42 \\
P<0.001\end{array}$ \\
\hline Improved quality of my life & - & - & $\begin{array}{l}\tau=0.32 \\
P<0.001\end{array}$ & $\begin{array}{l}\tau=0.33 \\
P<0.001\end{array}$ \\
\hline Improved quality of my cows' lives & - & - & - & $\begin{array}{l}\tau=0.34 \\
P<0.001\end{array}$ \\
\hline
\end{tabular}

${ }^{1} \mathrm{AMS}=$ automatic milking system. 
Most surveyed producers (86\%) would recommend transitioning to AMS to other farmers. Only $1 \%$ would not recommend AMS to other producers and 13\% stated the recommendation would depend on whom they were recommending the technology to, as some farmers are "less tech-savvy." Proportions of producer recommendations did not differ by brand $(P \geq 0.36)$.

\section{DISCUSSION}

This is the first study to provide information about how Canadian dairy producers experience the transition to AMS, and the first to describe experiences with cow training, challenges during the transition (and their solutions), and effect on quality of life. Producers experienced a positive transition to AMS and would recommend AMS to other dairy producers. Less than half of the AMS producers trained cows or heifers to use the AMS before the animal's first milking with the robot. Despite some challenges, producers perceived that AMS improved profitability, quality of their life and their cows' lives, and had met expectations.

Similar to the current study, in Sweden, the top 3 information sources used for making the adoption decision were other producers, supplier of AMS, and advisors (Bergman and Rabinowicz, 2013). Interestingly, unlike the Canadian producers surveyed in our study, the Swedish producers in the Bergman and Rabinowicz (2013) study were not satisfied with the level of support provided by the advisors and believed that the advisors were not knowledgeable enough about AMS.

The AMS companies often recommend a training program to help cows adapt to the AMS. Training usually entails bringing cows to the AMS unit from 1 to 4 times/d (without milking, but providing high concentrate feed) for 3 to $14 \mathrm{~d}$ before start-up (DeLaval International AB, 2008; Hulsen and Rodenburg, 2008). Producers in our study who trained cows used group sizes that were smaller than the recommended training group size of 25 to 30 cows (Hulsen and Rodenburg, 2008). Our study showed that producers took 1 wk to train cows or heifers to adapt to the AMS. In other studies where cows were trained (Jacobs and Siegford, 2012) or not trained (Spolders et al., 2004), it was reported that it took a similar average of 7 to $8 \mathrm{~d}$ for a cow to adapt to an AMS. In the current study, the average time for an entire herd to adapt was $30 \mathrm{~d}$, which is similar to what has been suggested by Rodenburg (2002). It was speculated that despite the reported benefits of providing exposure to the AMS before first milking (e.g., fewer fetch cows, positive effect on milking intervals and milk production; Jago and Kerrisk, 2011; Widegren, 2014), surveyed producers might have chosen not to train cows to use the AMS because of the extra time and effort needed to do so. Furthermore, it was observed that certain barn layouts, which house close-up cows and heifers in a space with no access to the AMS, restrict the ability to include pre-calving training.

A study conducted in Ontario, Canada, documented that producers culled an average of 0 to $3 \%$ more cows with AMS due to close teat placements, unusual udder conformation that made it difficult for the robot to scan for teats, and "lazy" cows that involuntarily attended milkings when otherwise normal in appearance and behavior (Rodenburg, 2002). In the current study, the proportion of a herd culled exclusively due to "laziness," as defined by Rodenburg (2002), fell within the higher end of this range, which may suggest that culling cows in AMS due to poor teat placement and udder conformation was less common than culling lazy cows.

The negative correlation between the statement "AMS has met expectations" and time since transition to AMS, which implied that satisfaction with AMS decreased with time, is understandable as older AMS units may start to require more maintenance or newer models of AMS may have improved and have less problems than older versions. However, rather than interpreting the older AMS farms as being less satisfied, it could be viewed that our understanding of this milking technology has improved, which has allowed more reasonable expectations from new AMS users. In addition, producers with more recently installed AMS units may be under the influence of postproduct rationalization, which occurs when a purchaser of an expensive product sees through product faults as a way to justify their purchase (Cohen and Goldberg, 1970). This bias may have influenced a higher score for meeting expectations in newer AMS farms.

Two other correlations showed that quality of producers' lives improved to a lesser extent on AMS farms with larger herd sizes, and that expectations with AMS were also met to a lesser extent on AMS farms with larger herd sizes. No differences were detected in herd size between producers who experienced an increase, decrease, or no change in milk yield or in bulk tank SCC (Tse et al., 2018), so the associations cannot be due to reduced milk production or quality. It was speculated that producers with larger herds would not score the statement "AMS has improved quality of my life" as positively as producers with smaller farms since larger farms would not be able to decrease the number of employees (i.e., employee management) to the same extent as smaller farms. However, no association was observed between the change in herd size and change in number of employees with the transition to AMS 
(Tse et al., 2018). Further research is required to fully understand the extent of these relationships and the possible causes for their negative associations.

Challenges experienced by the producers were diverse, but not unusual. Being on-call and feeling overwhelmed by the amount of information the AMS produced were challenges that have been experienced by other producers (e.g., Hansen, 2015). Changing practices and having less contact with cows were challenges that took time for producers to get used to. For some producers, physical contact with their cows plays a significant role in job satisfaction (Meskens et al., 2001). Among Swedish producers, having reduced contact with cows was an important reason for not installing AMS (Bergman and Rabinowicz, 2013).

As shown in the solutions expressed by producers in our study, and as documented by Hansen (2015), it is clear that experiences and opinions of other AMS farmers (local and international) are important to producers who are considering or in the process of transitioning to AMS. As such, it may be beneficial to implement an international, online, producer-based, AMS forum so knowledge can flow (more easily) between farmers. Furthermore, producers can make the transition easier by planning ahead in detail (e.g., finding a good contractor for renovations or building a new facility, and recruiting friends or hired-hands to help push cows through the robot the first few days), anticipating challenges that might not be a direct result of AMS (e.g., feet and leg issues when switching from tiestall to freestall housing), and opening the lines of communication and building a positive relationship with veterinarians, nutritionists, and the local AMS dealer so that a network of professionals is available to help with changes in cow health and technical issues with the AMS.

Overall, transitioning to AMS had a positive effect on the quality of producers' lives. Improvements to producers' lives with the transition to AMS were very similar to what other studies have documented abroad (e.g., in Australia, New Zealand, and Norway): more flexible working hours, which improved producers' family and social life (Molfino et al., 2014); improved health of producers with the reduced physical workload (see review by Meskens et al., 2001); as well as increased job satisfaction on AMS farms in New Zealand and Norway (Hansen, 2015; Woodford et al., 2015). Producers in the current study, like those in Australia (Molfino et al., 2014), felt their expectations around AMS were met, and like producers in Sweden (Bergman and Rabinowicz, 2013), would recommend transitioning to this new technology to others. Although the existence of a farm successor has been shown to increase the probability of investing in an AMS, less than half of our respondents switched to AMS as part of a farm succession plan.

\section{CONCLUSIONS}

In conclusion, producers experienced a positive transition to AMS; producers suggested they gained more time flexibility, found work to be less stressful and physically demanding, found employee management easier, and reported improve quality of their lives and their cows' lives. The majority of producers surveyed would recommend this technology to others. Our findings benchmark the experiences of Canadian dairy producers during the transition to, and use of, AMS, which will help producers make a more informed decision about adopting AMS and will make future transitions easier by detailing what should be expected of the change.

\section{ACKNOWLEDGMENTS}

The authors thank the Dairy Farmers of Canada (Ottawa, ON, Canada), University of Calgary Veterinary Medicine (UCVM; Calgary, AB, Canada), Agriculture and Agri-Food Canada (Ottawa, ON, Canada), and the BC Ministry of Agriculture (Duncan, BC, Canada) for their financial support. We thank Alberta Milk (Edmonton, AB, Canada), Dairy Farmers of Manitoba (Winnipeg, MB, Canada), Lely Canada (Woodstock, ON, Canada), and DeLaval Canada (Peterborough, ON, Canada) for providing access to AMS producers. The authors also thank Grace Kwong at UCVM for statistical advice and the collaborators used for regional data collection: Kelsey Chapman at UCVM; Ellen Watkiss and Joe Stookey at the University of Saskatchewan (Saskatoon, SK, Canada); Lisa Gordon at the University of Guelph, Kemptville Campus (Kemptville, ON, Canada); Meagan King at the University of Guelph, Main Campus (Guelph, ON, Canada); and Stephanie Dion, Jean-Michel Beaudoin, and Doris Pellerin at Laval University (Quebec City, QC, Canada).

\section{REFERENCES}

Bergman, K., and E. Rabinowicz. 2013. Adoption of the automatic milking system by Swedish milk producers. AgriFoods Economics Centre. Accessed Feb. 26, 2018. http://www.agrifood.se/Files/ AgriFood_WP20137.pdf.

Canadian Dairy Information Centre. 2016. Dairy facts and figures. Accessed Jun. 8, 2018. www.dairyinfo.gc.ca.

Cohen, J. B., and M. E. Goldberg. 1970. Dissonance product evaluation. J. Mark. Res. 7:315-321.

de Koning, C. J. A. M. 2010. Automatic milking-Common practice on dairy farms. Pages 52-67 Proc. First North Am. Conf. on Precision Dairy Management, Toronto, Canada. Accessed Jun. 8, 2018. http://www.precisiondairy.com/proceedings/s3dekoning.pdf.

DeLaval International AB. 2008. Instruction book VMS best practices [Brochure]. DeLaval International AB, Tumba, Sweden.

Ferland, J., E. Vasseur, M. Duplessis, E. A. Pajor, T. de Vries, and D. Pellerin. 2016. Economic impact of introducing automatic milking system on Canadian dairy farms. J. Anim. Sci. 94:600-601. 
Green, J., and N. Thorogood. 2013. Thematic content analysis. Pages 209-218 in Qualitative Methods for Health Research. 3rd ed. Sage Publications, Los Angeles, CA.

Hansen, B. G. 2015. Robotic milking-farmer experiences and adoption rate in Jaeren, Norway. J. Rural Stud. 41:109-117.

Hulsen, J., and J. Rodenburg. 2008. Robotic milking [Brochure]. Roodbont Publishers, Zutphen, the Netherlands.

Jacobs, J., and J. Siegford. 2012. Lactating dairy cows adapt quickly to being milked by an automatic milking system. J. Dairy Sci. 95:1575-1584.

Jago, J., and K. Kerrisk. 2011. Training methods for introducing cows to a pasture-based automatic milking system. Appl. Anim. Behav. Sci. 131:79-85.

Meskens, L., M. Vandermersch, and E. Mathijs. 2001. Implication of the introduction of automatic milking on dairy farms. Deliverable D2 from EU project Implications of the introduction of automatic milking on dairy farms' (QLK5 2000-31006). Accessed Jun. 8, 2018. http://www.automaticmilking.nl.

Molfino, J., K. Kerrisk, and S. C. García. 2014. Investigation into the labour and lifestyle impacts of automatic milking systems (AMS) on commercial farms in Australia. Pages 339-342 in Proc. 5th Australian Dairy Sci. Symp., Melbourne, Australia. Accessed Jun. 8, 2018. http://futuredairy.com.au/wp-content/uploads/2016/02/ 63MolfinoADSS2014.pdf

Reinemann, D. J., and D. J. Smith. 2000. Evaluation of automatic milking systems for the United States. Pages $232-238$ in Robotic
Milking Proc. Int. Symp., Lelystad, the Netherlands. Wageningen Pers, Wageningen, the Netherlands.

Rodenburg, J. 2002. Robotic milkers: What, where... and how much!!?? Pages 1-18 in Proc. Ohio Dairy Management Conf., Columbus, OH. Accessed Jun. 8, 2018. https://www.researchgate .net/publication/228503938_Robotic_milkers_What_where_and how much.

Spolders, M., U. Meyer, G. Flachowsky, and M. Coenen. 2004. Differences between primiparous and multiparous cows in voluntary milking frequency in an automatic milking system. Ital. J. Anim. Sci. 3:167-175.

Tse, C., H. W. Barkema, T. J. DeVries, J. Rushen, and E. A. Pajor. 2017. Effect of transitioning to automatic milking systems on producers' perceptions of farm management and cow health in the Canadian dairy industry. J. Dairy Sci. 100:2404-2414.

Tse, C., H. W. Barkema, T. J. DeVries, J. Rushen, and E. A. Pajor. 2018. Impact of automatic milking systems on producers' reports of milking labour management, milk production and milk quality. Animal. https://doi.org/10.1017/S1751731118000654.

Widegren, S. 2014. Introduction of heifers to an automatic milking system. BS Thesis. Dept. of Animal Nutrition and Management, Swedish Univ. of Agricultural Sciences, Uppsala.

Woodford, K. B., M. H. Brakenrig, and M. C. Pangborn. 2015. New Zealand case studies of automatic-milking-systems adoption. Pages 127-131 in Proc. N. Z. Soc. Anim. Prod., Dunedin, New Zealand. Accessed Jun. 8, 2018. http://www.sciquest.org.nz/node/142523. 